\title{
ARTICLE mTORC1 inhibitor RAD001 (everolimus) enhances non-small cell lung cancer cell radiosensitivity in vitro via suppressing epithelial-mesenchymal transition
}

\author{
Yu Chen ${ }^{1}$, Wen-wen $\mathrm{LI}^{1}$, Ping Peng ${ }^{1}$, Wei-heng Zhao ${ }^{1}$, Yi-jun Tian ${ }^{1}$, Yu Huang ${ }^{1}$, Shu Xia ${ }^{1}$ and Yuan Chen ${ }^{1}$
}

Resistance to radiotherapy causes non-small cell lung cancer (NSCLC) treatment failure associated with local recurrence and metastasis. Thus, understanding the radiosensitization of NSCLC cells is crucial for developing new treatments and improving prognostics. mTORC1 has been shown to regulate tumor cell radiosensitivity, but the underlying mechanisms are unclear. Moreover, mTORC1 also regulates epithelial-mesenchymal transition (EMT) that is important to metastasis and recurrence. In this study we explored whether mTORC1 regulated NSCLC cell radiosensitivity by altering EMT. We performed immunohistichemical analysis using tumor, adjacent and normal tissues from 50 NSCLC patients, which confirmed significantly elevated mTOR protein expression in NSCLC tissue. Then we used $\mathrm{NCl}-\mathrm{H} 460$ and $\mathrm{NCl}-\mathrm{H} 661$ cell lines to examine the effects of the mTORC1 inhibitor RAD001 (everolimus) on in vitro radiosensitivity, protein expression and dose-survival curves. RAD001 (10 nmol/L) significantly inhibited the mTORC1 pathway in both the cell lines. Pretreatment with RAD001 $(0.1 \mathrm{nmol} / \mathrm{L})$ enhanced the radiosensitivity in NCI-H661 cells with wild-type PIK3CA and KRAS but not in $\mathrm{NCl}-\mathrm{H} 460$ cells with mutant PIK3CA and KRAS; the sensitivity enhancement ratios in the two NSCLC cell lines were 1.40 and 1.03, respectively. Furthermore, pretreatment with RAD001 $(0.1 \mathrm{nmol} / \mathrm{L})$ significantly decreased the migration and invasion with altered expression of several EMT-associated proteins (significantly increased E-cadherin and decreased vimentin expression) in irradiated $\mathrm{NCl}-\mathrm{H} 661$ cells. Publicly available expression data confirmed that irradiation affected mTOR and EMT-associated genes at the transcript level in NSCLC cells. These results suggest that mTORC1 inhibition enhances the in vitro radiosensitivity of NSCLC cells with wild-type PIK3CA and KRAS by affecting EMT. Our preclinical data may provide a potential new strategy for NSCLC treatment.

Keywords: Non-small-cell lung cancer (NSCLC); NCl-H460 cell line; NCl-H661 cell line; Radiosensitivity; mTOR; RAD001 (everolimus); PIK3CA; KRAS; Epithelial-mesenchymal transition

Acta Pharmacologica Sinica (2019) 40:1085-1094; https://doi.org/10.1038/s41401-019-0215-y

\section{INTRODUCTION}

Radiotherapy is crucial for the treatment of locally advanced nonsmall cell lung cancers (NSCLCS). However, resistance to radiotherapy has been shown to contribute to treatment failure, recurrence, and metastasis. While the mechanisms involved are largely unknown, recent evidence has emerged showing that tumor cell radiation sensitivity (radiosensitivity) involves several signal transduction pathways. In particular, the PI3K/AKT/mTOR pathway plays a crucial role in cancer cell growth, survival, and proliferation [1]. In turn, the inhibition of PI3K, RAS, and AKT has been shown to radiosensitize cancer cell lines [2]. PI3K is a heterodimeric kinase composed of a p85 regulatory subunit and a p110 catalytic subunit that catalyzes the phosphorylation of phosphatidylinositol-4,5-bisphosphate (PIP2) into phosphatidylinositol-3,4,5-triphosphate (PIP3). This phosphorylation activates various downstream effectors, including AKT, which is a serine/ threonine kinase involved in triggering a cascade of responses that are linked to cancer development [3]. Importantly, these responses include the activation of the mammalian target of rapamycin (mTOR) protein, a serine/threonine protein kinase that couples energy and nutrient abundance to growth and division in eukaryotes [4]. There are two multiprotein complexes that include mTOR, mTORC1, and mTORC2. mTORC1 is partially sensitive to rapamycin and its analogs, whereas $\mathrm{mTORC2}$ is believed to be rapamycin-insensitive [5]. The Ras/Raf/MEK pathway is also involved in activating mTORC1 via various growth factors and the extracellular signal-regulated kinase (ERK) protein. ERK phosphorylates and inactivates tuberous sclerosis complex 2 (TSC2), promoting mTORC1 activation [6].

An important contributor to recurrence and metastasis is epithelial-mesenchymal transition (EMT), an abiological process in which epithelial cells lose their polarity. During this process, cells are reprogrammed to express a mesenchymal phenotype, losing their differentiated phenotype and tight cell-cell junctions. Markers of EMT include loss of cell-cell adhesion, reorganization of the actin cytoskeleton, and the development of increased migratory characteristics. EMT is often accompanied by the loss of epithelial markers, such as E-cadherin, and an increase in mesenchymal markers, such as vimentin [7]. Chronic exposure to radiation or chemotherapeutic drugs, including cisplatin and

${ }^{1}$ Department of Oncology, Tongji Hospital, Tongji Medical College, Huazhong University of Science and Technology, Wuhan 430030, China Correspondence: Shu Xia (xiashutj@hotmail.com) or Yuan Chen (chenyuan008@163.com)

Received: 15 June 2018 Accepted: 16 January 2019

Published online: 22 February 2019 
various taxanes, can lead to fusiform morphogenesis in NSCLC cells, increasing the expression of EMT-related proteins [8]. Importantly, NSCLC cells that undergo EMT contribute to the development of malignancy. Additionally, E-cadherin loss may promote tumor radioresistance by affecting DNA repair and cell cycle checkpoints [9]. It has also been hypothesized that inhibition of the mTOR signaling pathway with rapamycin may attenuate cancer cell migration and invasion in colorectal cancer (CRC). This hypothesis is supported by experiments showing that knockdown of mTORC1 and mTORC2 induces mesenchymal-epithelial transition (MET) and enhanced chemosensitivity in CRC cells [10]. Therefore, despite some studies finding that $\mathrm{MTORC} 1$ can regulate the EMT processes in some types of tumors, there has been little investigation into the relationships between NSCLC cell radiosensitivity and EMT. To investigate this further, our study examined the effects of an mTORC1 inhibitor on radiosensitivity, EMT-associated protein levels, and dose-survival curves using two NSCLC cell lines ( $\mathrm{NCl}-\mathrm{H} 460$ and $\mathrm{NCl}-\mathrm{H} 661)$.

\section{MATERIALS AND METHODS}

Cell lines and reagents

$\mathrm{NCl}-\mathrm{H} 460$ and $\mathrm{NCl}-\mathrm{H} 661$ human NSCLC cell lines were obtained from the cell bank of the Committee on Type Culture Collection of the Chinese Academy of Sciences (Shanghai, China) and were maintained at $37^{\circ} \mathrm{C}$ with $5 \% \mathrm{CO}_{2}$ with RPMI 1640 medium (Gibco; Thermo Fisher Scientific, Waltham, MA, USA) supplemented with $10 \%$ fetal bovine serum (FBS; Gibco; Thermo Fisher Scientific, Waltham, MA, USA). The $\mathrm{NCl}-\mathrm{H} 460$ cell line carries mutations in PIK3CA and KRAS [11, 12], whereas the $\mathrm{NCl}-\mathrm{H} 661$ cell line has wildtype alleles for both [11, 13]. The mTORC1 inhibitor RAD001 (everolimus) was provided by Novartis Pharmaceuticals (Basel, Switzerland) and was dissolved in DMSO before being stored at $-20^{\circ} \mathrm{C}$ (Sigma-Aldrich, St. Louis, MO, USA). Drugs were diluted in culture medium to achieve the required concentrations before use.

Patients and immunohistochemistry

In total, 150 paraffin-embedded tissues from 50 NSCLC patients were acquired from the Tongji Hospital Tissue Bank. The study was approved by the Institutional Review Board (IRB ID: TJ-C20151236) of Tongji Hospital, Tongji Medical College, Huazhong University of Science and Technology. All study participants provided written informed consent before tissues were collected. Diagnosis was confirmed in all cases by routine histopathological examination, and the diagnoses were divided into three groups: primary tumor, adjacent tissues, and normal tissues. Histological slides were then prepared and incubated overnight at $4{ }^{\circ} \mathrm{C}$ with a primary antimTOR antibody (1:50; Cell Signaling Technology, Inc., Danvers, MA, USA). The degree of mTOR staining was then scored blindly by two independent pathologists unaware of the clinical characteristics of the patients. The scoring criteria followed a semiquantitative seven-tier system developed by Allred et al. [14] that assessed the percentage of positive cells (none $=0 ;<10 \%=1$; $10-50 \%=2 ;>50 \%=3$ ) and the intensity of the staining (none = 0 ; weak $=1$; intermediate $=2$; and strong $=3$ ). The percentage and intensity scores were combined to give a final immunoreactivity score ranging from 0 to 6 [14].

\section{Cell proliferation assays}

The effect of the RAD001 inhibitor on cell proliferation was determined using a 3-(4,5-dimethylthiazol-2-yl)-2,5-diphenyltetrazolium bromide colorimetric assay (MTT; Sigma-Aldrich, St. Louis, MO, USA). Cells were seeded on 96-well tissue culture plates at a density of 2000-4000 cells per well and cultured overnight to facilitate attachment. The cells were then treated with a range of RAD001 concentrations from 1000 to $0.1 \mathrm{nM}$. Each concentration was tested over at least five replicates. Control cells were treated with the same volumes of vehicle DMSO. After $72 \mathrm{~h}$ of incubation, $10 \mu \mathrm{L}$ of MTT solution was added to each well, and formazan crystals were solubilized in $100 \mu \mathrm{L}$ of DMSO after $4 \mathrm{~h}$. Absorbance was measured at $490 \mathrm{~nm}$ using a 96-well microplate reader (BioRad, Hercules, CA, USA), and the concentrations that resulted in $50 \%$ cell growth inhibition $\left(\mathrm{IC}_{50}\right)$ were calculated using GraphPad Prism version 5.01 for Windows (GraphPad Software, La Jolla, CA, USA).

\section{Western blot analysis}

Cells were cultured for $24 \mathrm{~h}$ with RAD001 at the indicated concentrations. The cells were then either exposed to $4 \mathrm{~Gy}$ X-ray irradiation using an RS-2000 biological research irradiator (200 cGy/min; Rad Source Technologies, Buford, GA, USA) or left as controls. Cells were collected, washed twice in ice-cold phosphatebuffered saline (PBS) and lysed in ice-cold lysis buffer containing $20 \mathrm{mM}$ Tris ( $\mathrm{pH} 7.5), 150 \mathrm{mM} \mathrm{NaCl}, 1 \%$ Triton X-100, $2.5 \mathrm{mM}$ sodium pyrophosphate, $1 \mathrm{mM} \beta$-glycerophosphate, $1 \mathrm{mM} \mathrm{Na} \mathrm{VO}_{4}$, $1 \mathrm{mM}$ EDTA, and $1 \mu \mathrm{g} / \mathrm{mL}$ leupeptin with $1 \mathrm{mM} \mathrm{PMSF}$ and $1 \mathrm{mM}$ phosphatase inhibitors. The cells were then centrifuged at $13,000 \times g$ for $5 \mathrm{~min}$ at $4{ }^{\circ} \mathrm{C}$, and the supernatant was collected. The supernatant was then boiled with loading buffer for $5 \mathrm{~min}$ before being stored at $-80^{\circ} \mathrm{C}$. Before analysis, protein concentrations were determined using a BCA protein assay kit (Thermo Fisher Scientific, Waltham, MA, USA). Equivalent amounts of protein from each sample were electrophoresed on 10\% SDSPAGE gels, transferred to nitrocellulose membranes, and incubated overnight at $4{ }^{\circ} \mathrm{C}$ with either anti-p70S6K (1:5000; N-term; Epitomics; Abcam, Cambridge, UK), anti-vimentin (1:5000; Epitomics; Abcam, Cambridge, UK), anti-phospho-p70S6K (1:1000; Thr389; Cell Signaling Technology, Inc., Danvers, MA, USA), or antiE-cadherin antibodies (1:1000; Cell Signaling Technology, Inc., Danvers, MA, USA). Subsequently, proteins were incubated for $1 \mathrm{~h}$ with goat anti-rabbit peroxidase-conjugated secondary antibody at $25^{\circ} \mathrm{C}$ (1:2000; Boster Bio, Pleasanton, CA, USA). Protein bands were revealed using the $\mathrm{ECL}$ western blotting substrate (Thermo Fisher Scientific, Waltham, MA, USA).

\section{Immunofluorescence assays}

For immunofluorescent staining, the cells were grown on chambered slides in 24-well tissue culture plates as previously reported [15]. The cells were pretreated with RAD001 or control vehicle $24 \mathrm{~h}$ before irradiation and were then fixed with $4 \%$ paraformaldehyde (PFA) at 0.5 and $24 \mathrm{~h}$ after $4 \mathrm{~Gy}$ X-ray irradiation or sham-irradiation. The anti-phospho-H2A.X antibody was purchased from Abcam (pS139, Abcam, Cambridge, UK), and the secondary fluorescein-labeled (FITC)-conjugated goat anti-rabbit antibody was purchased from Boster Bio (Pleasanton, CA, USA). Images were acquired using an Olympus confocal laser scanning microscope (magnification: $\times 200$ ) and accessory software (Olympus Corporation, Tokyo, Japan).

\section{Clonogenic survival assays}

$\mathrm{NCl}-\mathrm{H} 460$ and $\mathrm{NCl}-\mathrm{H} 661$ cells were seeded in triplicate onto $60-\mathrm{mm}$ dishes at concentrations suitable to promote the development of 50 to 100 colonies per dish and were allowed to attach for $24 \mathrm{~h}$. The cells were pretreated with or without $0.1 \mathrm{nM}$ RAD001 for $24 \mathrm{~h}$ and then exposed to $0,2,4,6$, or $8 \mathrm{~Gy} \mathrm{X}$-rays. The medium was then replaced with drug-free RPMI 1640, and the cells were cultured for 14 days with $5 \% \mathrm{CO}_{2}$. Colonies were then stained with $0.5 \mathrm{~mL}$ of $0.1 \%$ crystal violet (Sigma-Aldrich, St. Louis, $\mathrm{MO}$, USA) solution for $1 \mathrm{~h}$ and counted using light microscopy at $40 \times$ magnification. A viable colony was defined as having at least 50 cells after 14 days of growth. The surviving fractions of treated cells were established by normalizing the values to the plating efficiency of the control cells that did not undergo irradiation. Cell survival was plotted as a function of dose and was fitted using GraphPad Prism version 5.01 for Windows (GraphPad Software, 
a
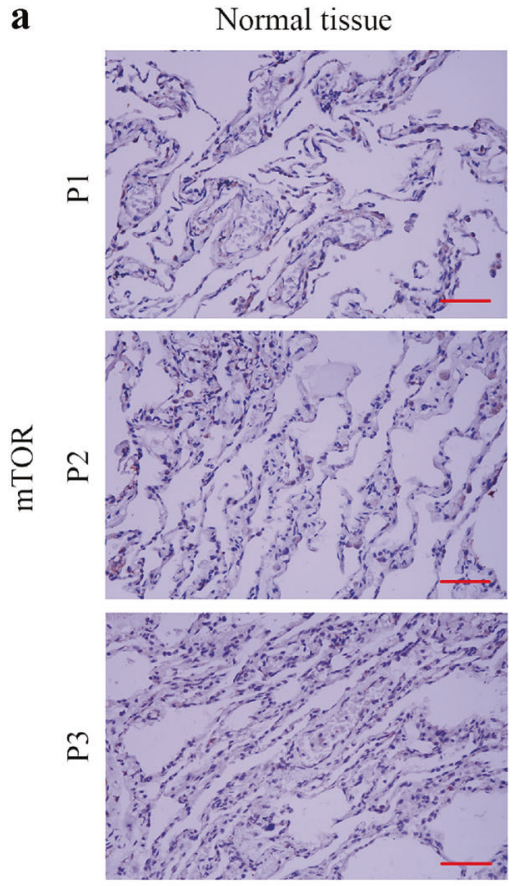

Adjacent tissue
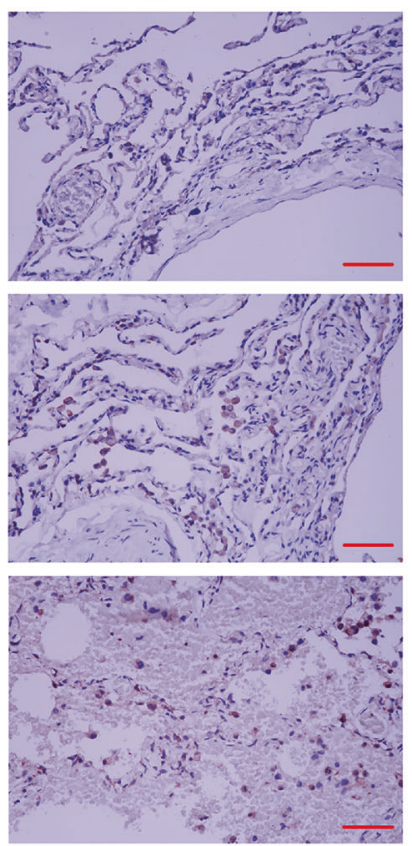

Tumor
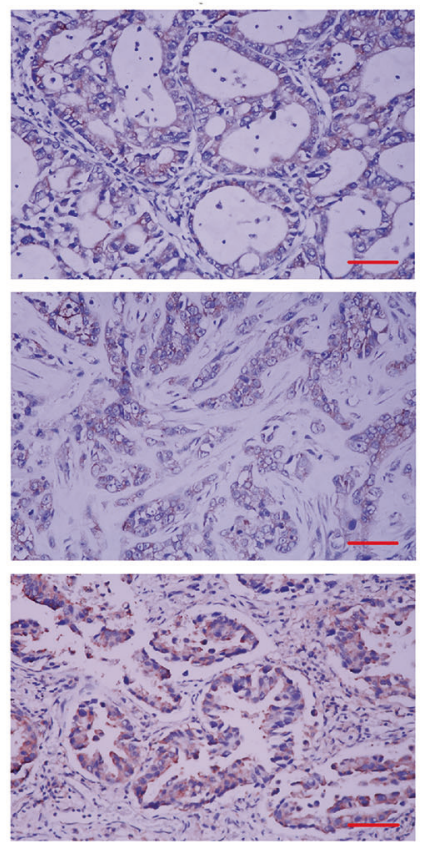

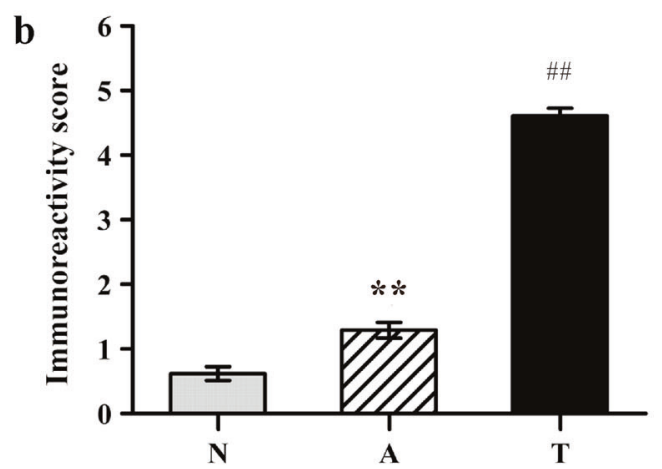

Fig. 1 Expression of mTOR in samples isolated from patients with NSCLC. a Expression of mTOR in normal tissues, adjacent tissues, and tumors $(400 \times ; n=50$ cases; $b a r=50 \mu \mathrm{m})$. b Analysis of immunoreactivity scores in tumors, adjacent tissues, and normal tissues. ${ }^{* *} P<0.01$ vs. normal tissue ${ }^{\# \#} P<0.01$ vs. normal tissue $n=50$

La Jolla, CA, USA) and a multi-target single hit model $\mathrm{SF}=1-\left(1-\mathrm{e}^{-D / D_{0}}\right)^{N}$, where SF is cell survival, $D$ is the dose of radiation, and $D_{0}$ and $N$ are constants. $\mathrm{SF}_{2}$ (the surviving fraction of cells at $2 \mathrm{~Gy}$ ) was calculated from the actual data. The SER (sensitivity enhancement ratio) was defined as $\mathrm{SER}=D_{0}$ (X-ray)/ $D_{0}$ (X-ray plus RAD001) [16].

Invasion and migration assay

The invasion assays were performed using Matrigel (Corning, Kennebunk, ME, USA) in 24-well transwell chambers (Corning, Kennebunk, ME, USA) as previously described [17]. The $1 \times 10^{5}$ $\mathrm{NCl}-\mathrm{H} 460$ and $\mathrm{NCl}-\mathrm{H} 661$ cells were added to the upper compartment of the chamber. After overnight incubation, the cells were pretreated with $0.1 \mathrm{nM}$ RAD001 or vehicle for $24 \mathrm{~h}$ and then exposed to $4 \mathrm{~Gy}$ irradiation. Then, the medium of the upper compartment of the chamber was changed to 1\% FBS RPMI 1640, and the chemoattractant used in the lower compartment was $20 \%$ FBS. After $24 \mathrm{~h}$, the cells were fixed with $4 \%$ paraformaldehyde and stained with $0.1 \%$ crystal violet. The invasive cells were counted in four different fields with an inverted fluorescence microscope (magnification: $\times 100$ ). The migration assay was similar to the invasion assay described above, except that $4 \times 10^{4}$ cells in serum-free RPMI 1640 medium were added to the upper compartment without the Matrigel, and the chemoattractant used was $10 \%$ FBS. All experiments were carried out in triplicate.

Gene expression array analysis

The public ArrayExpress database was investigated to identify appropriate assays for analysis. The GSE10547 dataset (first made public on April 15, 2008 and last updated on March 19, 2012) using the GPL6495 platform was determined to be the most appropriate [18]. This dataset originated from a study that used polysome-bound RNA to examine gene translation profiles across a series of tumor and normal cell lines. To better define genes whose expression levels were influenced by ionizing radiation, cell lines in the study were exposed to 2 Gy X-ray, and polysome-bound RNA was isolated $6 \mathrm{~h}$ later before being subjected to microarray analysis. The dataset used the human non-small cell lung cancer cell line HOP62 that harbored a KRAS gene mutation and was exposed to either $2 \mathrm{~Gy}$ irradiation or was sham-irradiated across two biological replicates [18, 19]. We isolated 29 mTOR and EMT signaling pathway-related genes from the ArrayExpress data using KEGG pathway information and then performed unsupervised clustering with the "pheatmap" package of the R statistical program software. 

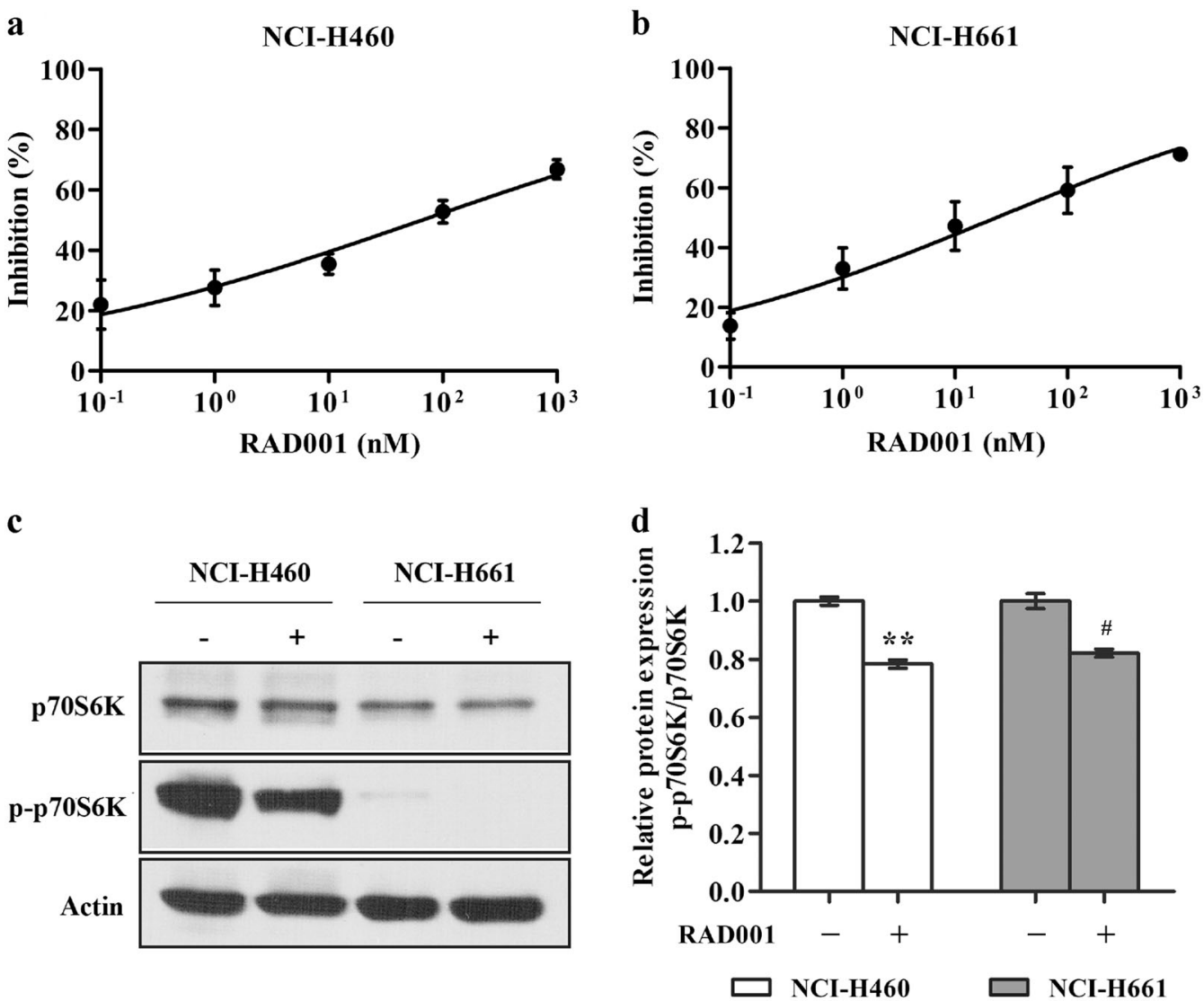

Fig. 2 The mTOR inhibitor RAD001 is effective at inhibiting the growth of NSCLC cells and mTORC1 signaling. $\mathbf{a}, \mathbf{b} \mathrm{NCl}-\mathrm{H} 460$ and NCI-H661 cells were exposed to different concentrations of RAD001 for $72 \mathrm{~h}$ (ranging from 0.1 to $1000 \mathrm{nM}$ ). Data are expressed as the percentage of inhibition of cell proliferation. The mean values of three independent measurements $( \pm$ SD) are shown. c Representative western blots of p70S6K and p-p70S6K expression in NSCLC cell lines treated with $10 \mathrm{nM}$ RAD001 for $24 \mathrm{~h}$. $\mathbf{d}$ Analysis of relative p-p70S6K protein expression in the two cell lines. ${ }^{* *} P<0.01$ vs. control. ${ }^{\#} P<0.05$ vs. control. $n=3$

Statistical analysis

Statistical analysis between groups was conducted by independent sample Student's t-test. All statistical analyses were performed using SPSS v18.0 software (SPSS; IBM, Armonk, NY, USA), and the data are presented as the mean \pm standard deviation (SD). Differences at a threshold of $P<0.05$ were considered significant.

\section{RESULTS}

Expression of mTOR protein is elevated in NSCLC tissue

To assess the extent of mTOR pathway alterations in NSCLC, we analyzed mTOR protein expression in tumors, adjacent tissues, and normal tissues that were isolated from 50 patients with NSCLC. Each sample was assigned an immunoreactivity score ranging from 0 to 6 , representative images were obtained and analyses for each tissue type were performed (Fig. 1). The normal lung tissue showed negative or mild cytoplasmic staining for mTOR, whereas the primary tumors and matched adjacent tissues exhibited higher levels of diffuse cytoplasmic mTOR staining. These findings show that mTOR protein is overexpressed in primary NSCLC tissues and adjacent tissues.

Effect of the mTORC1 inhibitor RAD001 on cell proliferation and the mTOR signaling pathway

We next performed proliferation assays to determine the effects of treatment with the mTORC1 inhibitor RAD001 on two NSCLC cell lines with different PIK3CA and KRAS genotypes. This demonstrated that RAD001 treatment caused mild but significant growth inhibition and affected cell proliferation in a dose-dependent manner to varying extents in the different cell lines (Fig. 2). In the $\mathrm{NCl}-\mathrm{H} 460$ cells, the $\mathrm{IC}_{50}$ of RAD001 was $65.94 \pm 1.35 \mathrm{nM}$ (Fig. 2a) but was $23.18 \pm 1.34 \mathrm{nM}$ in the $\mathrm{NCl}-\mathrm{H} 661$ cells (Fig. 2b). Based on these $I C_{50}$ values, we calculated the $I C_{20}$ and maximum sensitization concentrations of $\mathrm{NCl}-\mathrm{H} 460$ and $\mathrm{NCl}-\mathrm{H} 661$ as 0.15 and $0.13 \mathrm{nM}$, respectively. We therefore chose a concentration of 0.1 $\mathrm{nM}$ to sensitize the two cell lines.

To further explore the effects of RAD001 on mTOR signaling, we examined the expression of p70S6K and p-p70S6K in the two cell lines exposed to $10 \mathrm{nM}$ RAD001 for $24 \mathrm{~h}$. p70S6K is an important downstream effector of mTOR, and its phosphorylation is effectively inhibited by rapamycin-analog treatment [20]. Our data showed a decrease in the phosphorylation of p70S6K at position Thr389 in the two cell lines (Fig. 2c, d). This highlights the importance of the mTOR signaling pathway in the proliferation of NSCLC cells, suggesting that sensitization with RAD001 may elicit an antitumor effect.

Pretreatment with RAD001 increases $\mathrm{Y}-\mathrm{H} 2 \mathrm{AX}$ formation in response to radiation

To assess the effects of mTORC1 inhibition and radiation on DNA repair, we examined $\mathrm{y}-\mathrm{H} 2 \mathrm{AX}$ staining as a biomarker for radiationinduced DNA double strand breaks (DSBs). $\gamma-\mathrm{H} 2 \mathrm{AX}$ foci were quantified by confocal microscopy before irradiation and 0.5 and $24 \mathrm{~h}$ after irradiation with $4 \mathrm{~Gy}$ X-ray. We found that pretreatment with $0.1 \mathrm{nM}$ RAD001 to inhibit mTORC1 increased the generation of $\mathrm{y}-\mathrm{H} 2 \mathrm{AX}$ foci in $\mathrm{NCl}-\mathrm{H} 661$ cells at the 0.5 and $24 \mathrm{~h}$ time points after $4 \mathrm{~Gy}$ irradiation, indicating an increased abundance of DSBs. 
a
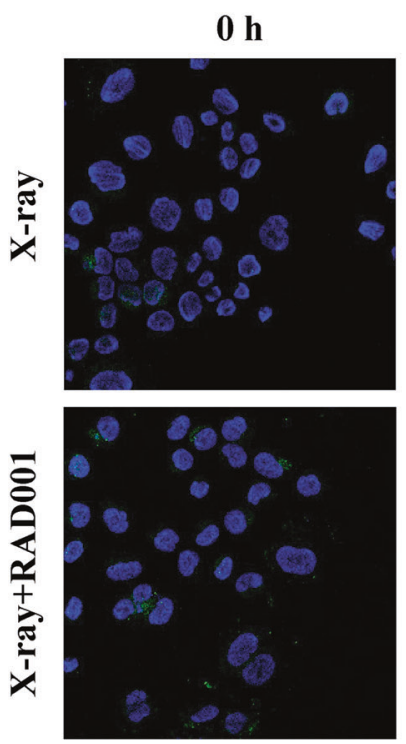

b
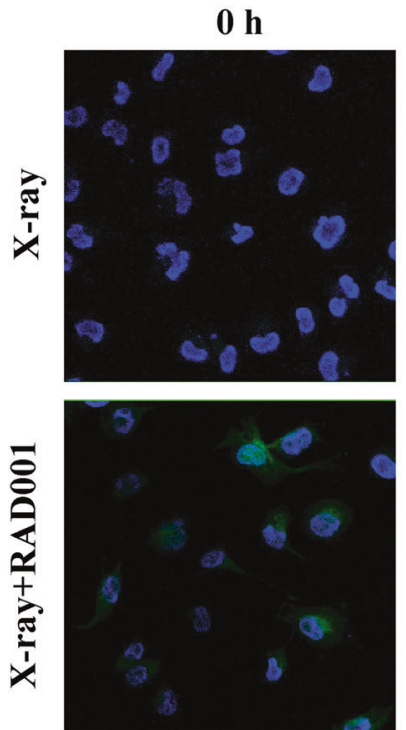

NCI-H460

$0.5 \mathrm{~h}$
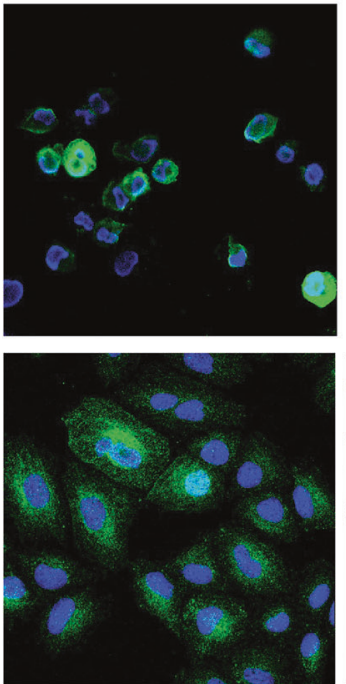

NCI-H661

$0.5 \mathrm{~h}$
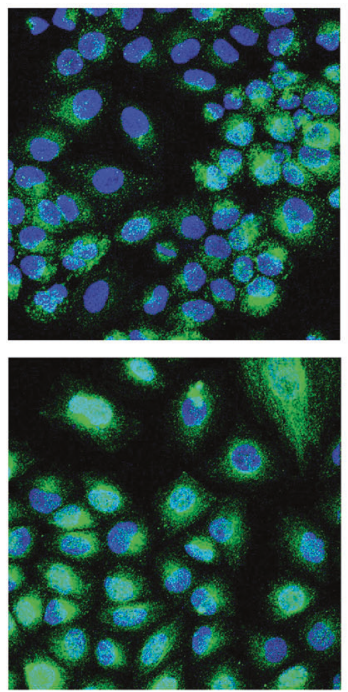

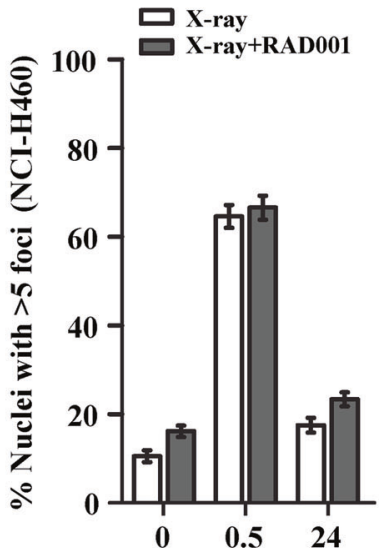

Time after 4 Gy (h)

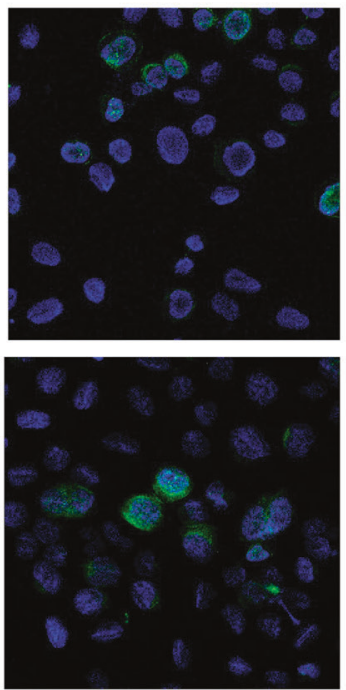

d
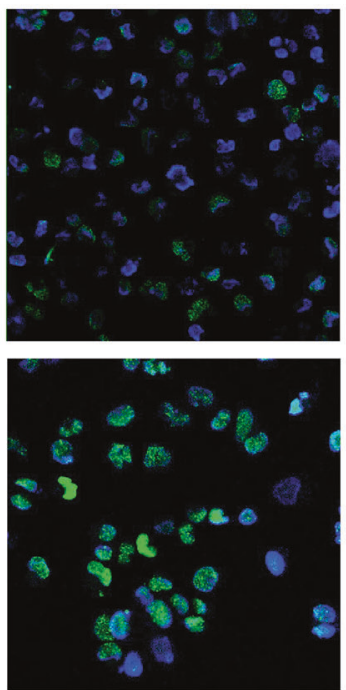

Fig. 3 Quantification of the residual $\gamma-\mathrm{H} 2 \mathrm{AX}$ foci in the two cell lines, with or without RAD001 treatment, 0.5 and $24 \mathrm{~h}$ after irradiation or sham-irradiation. a, b Representative images showing $\gamma-\mathrm{H} 2 \mathrm{AX}$ staining (indicative of double strand breaks) in $\mathrm{NCl}-\mathrm{H} 460$ and $\mathrm{NCl}-\mathrm{H} 661$ cells pretreated with or without $0.1 \mathrm{nM}$ RAD001 for $24 \mathrm{~h}$ and then exposed to $4 \mathrm{~Gy}$ X-rays. c, d Percentage of nuclei with five or more $\gamma$ - $\mathrm{H} 2 \mathrm{AX}$ foci after exposure to $4 \mathrm{~Gy}$, with or without RAD001 treatment, plotted against time. The data shown are expressed as the mean \pm SD of three independent experiments. $\mathrm{NCl}-\mathrm{H} 460 P=0.06480 .5 \mathrm{~h}$ vs. control. $P=0.050624 \mathrm{~h}$ vs. control. $\mathrm{NCl}-\mathrm{H} 661{ }^{* *} P<0.010 .5 \mathrm{~h}$ vs. control. ${ }^{\#} P<0.0524 \mathrm{~h}$ vs. control. $n=3$

Table 1. Radiobiological parameters of dose-survival curves

\begin{tabular}{|c|c|c|c|c|c|}
\hline Curve & $D_{0}$ & $D_{\mathrm{q}}$ & $N$ & $\mathrm{SF}_{2}$ & SER \\
\hline $\mathrm{NCl}-\mathrm{H} 460$ & 2.41 & 2.89 & 3.32 & $0.79 \pm 0.03$ & \\
\hline $\mathrm{NCl}-\mathrm{H} 460+\mathrm{RAD} 001$ & 2.34 & 2.43 & 2.83 & $0.76 \pm 0.02^{\mathrm{a}}$ & 1.03 \\
\hline $\mathrm{NCl}-\mathrm{H} 661$ & 2.24 & 1.93 & 2.36 & $0.67 \pm 0.02$ & \\
\hline $\mathrm{NCl}-\mathrm{H} 661$ + RAD001 & 1.60 & 1.37 & 2.36 & $0.55 \pm 0.04^{b^{* *}}$ & 1.40 \\
\hline \multicolumn{6}{|c|}{$\begin{array}{l}D_{0} \text { mean lethal dose, } D_{\mathrm{q}} \text { quasi-threshold dose, } N \text { extrapolation number, } \\
S F_{2} \text { surviving fraction at } 2 \mathrm{~Gy}, S E R \text { sensitivity enhancement ratio } \\
\text { a } P=0.174 \text { vs. CON. }{ }^{b^{* *}} P=0.007<0.01 \text { vs. CON }\end{array}$} \\
\hline
\end{tabular}

However, this change was not apparent in $\mathrm{NCl}-\mathrm{H} 460$ cells and was the same as the results obtained in the control cells (Fig. 3).

mTORC1 inhibition significantly enhances the radiosensitivity of $\mathrm{NCl}-\mathrm{H} 661$ cells

To examine the effects of mTORC1 inhibition on cellular radiosensitivity, NSCLC cells were incubated with $0.1 \mathrm{nM}$ RAD001 for $24 \mathrm{~h}$ to sensitize them prior to radiation. Cells were then allowed to form colonies for 14 days. The number of colonies containing more than 50 cells was counted and plotted after normalizing against the effect of RAD001 alone using control cells (Table 1). Dose-survival curves indicated that pretreatment with RAD001 suppressed the clonogenic survival of both $\mathrm{NCl}-\mathrm{H} 460$ and $\mathrm{NCl}-\mathrm{H} 661$ cells after different doses of radiation (Fig. 4). The 

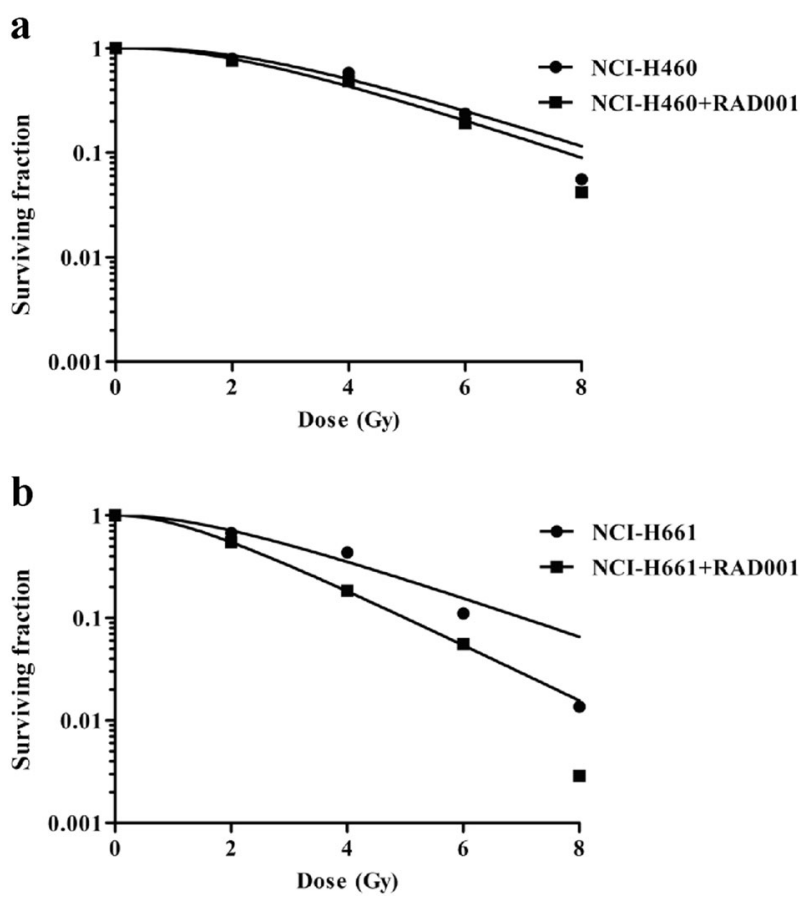

Fig. 4 Dose-survival curves derived from clonogenic survival assays over 14 days. a NCl-H460 and b NCl-H661 cells were treated with 0.1 nM RAD001 for $24 \mathrm{~h}$ and exposed to different levels of X-ray radiation $(2,4,6$, or $8 \mathrm{~Gy})$. The data shown are expressed as the mean \pm s.d. of at least three independent experiments

sensitivity enhancement ratios (SERs) of the $\mathrm{NCl}-\mathrm{H} 460$ and $\mathrm{NCl}-$ H661 cells were 1.03 and 1.40, respectively. This result suggests that mTORC1 inhibition was more effective at radiosensitizing $\mathrm{NCl}$ $\mathrm{H} 661$ cells with wild-type PIK3CA and KRAS in vitro than $\mathrm{NCl}-\mathrm{H} 460$ cells.

Effects of mTORC1 inhibition on migration and invasion of irradiated NSCLC cell lines

EMT is regarded as a key reversible step that facilitates tumor migration, invasion, and metastasis. We used $\mathrm{NCl}-\mathrm{H} 460$ and $\mathrm{NCl}-$ $\mathrm{H} 661$ cells to determine the effects of RAD001 on the migration and invasion of irradiated NSCLC. As shown in Fig. 5, pretreatment with RAD001 for $24 \mathrm{~h}$ before irradiation significantly decreased the migration and invasion of $\mathrm{NCl}-\mathrm{H} 661$ cells compared with that of the control group (Fig. 5a, b). The absolute numbers of cells migrating and invading through the membrane into the lower compartment of the chamber in the RAD001 pretreatment before irradiation groups were less than those in the control groups. However, this change was inconspicuous in $\mathrm{NCl}-\mathrm{H} 460$ cells compared with that in the control groups (Fig. $5 c$, d).

Activation of the mTORC1 pathway with EMT-associated genes and proteins altered in NSCLC cell lines after irradiation To further explore the mechanisms of genotype-dependent radiosensitivity after RAD001 treatment, we first evaluated the alteration of the downstream effectors p70S6K and p-p70S6K to explore whether the radiation could activate the mTOR pathway. The results demonstrated that radiation led to increased expression of p-p70S6K in both cell lines (Fig. 6a, b). However, pretreatment with RAD001 $24 \mathrm{~h}$ before irradiation reduced the expression of p-p70S6K in NCl-H661 cells; this effect was not notable in $\mathrm{NCl}-\mathrm{H} 460$ cells (Fig. $6 \mathrm{a}, \mathrm{b}$ ). Then, we evaluated the expression of various EMT-associated proteins, including E-cadherin and vimentin. Epithelial cells predominantly express E-cadherin, whereas mesenchymal cells express vimentin, $\mathrm{N}$ cadherin, and fibronectin. The expression of these biomarkers can therefore be used to characterize EMT [21]. Our western blot analysis revealed differences in expression of E-cadherin and vimentin in $\mathrm{NCl}-\mathrm{H} 661$ cells after pretreatment with RAD001 for 24 $\mathrm{h}$ and subsequent $4 \mathrm{~Gy}$ X-ray irradiation (Fig. 6d). Specifically, inhibition of mTORC1 led to increased expression of E-cadherin and decreased vimentin expression compared to the expression levels in the control cells (Fig. 6f). However, no changes were observed in the $\mathrm{NCl}-\mathrm{H} 460$ cells (Fig. $6 \mathrm{c}$, e). To further validate our data at the mRNA transcript level, we used publicly available data from the ArrayExpress database to examine the expression of genes involved in the mTOR and EMT signaling pathways in HOP62 cells exposed to either $2 \mathrm{~Gy}$ X-ray or sham-irradiation. Similar to the $\mathrm{NCl}-\mathrm{H} 460$ cell line examined in our study, the HOP62 NSCLC cell line harbors a KRAS mutation. As shown in Fig. 7, the expression levels of several mTOR and EMT signaling pathway transcripts, including PIK3CA, PTEN, CDH1, TWIST1, and VIM, were altered after irradiation.

\section{DISCUSSION}

Our study revealed that the mTOR signaling pathway is involved in regulating NSCLC cell radiosensitivity, likely by affecting EMT. Recently, there has been increasing interest in examining the relationships between radiation and EMT, including how EMT affects radiosensitivity. However, the links between NSCLC mutations and the role of the mTOR signaling pathway in EMT and radioresistance remained unclear. Our data indicate that pharmacological inhibition of mTORC1 significantly increases the radiosensitivity of $\mathrm{NCl}-\mathrm{H} 661$ cells in vitro by affecting EMT. Our data build on previous studies that highlight the contribution of the mTOR pathway and EMT to the radiosensitivity of tumor cells. Previously, it has been reported that low doses of ionizing radiation can induce EMT in breast cancer cells and that Ecadherin loss associated with EMT can promote radioresistance in human tumor cells $[21,22]$. Inhibition of mTOR signaling in the SW480 human colon cancer cell line was also found to increase Ecadherin levels, suggesting that mTOR inhibition may promote radiosensitivity [10]. Indeed, a recent study using the dual mTORC1 and mTORC2 inhibitor PP242 to affect the mTOR pathway revealed radiosensitizing effects in AMC-HN-9 and U87 cancer cells [23]. Interestingly, these two cell lines harbor the same wild-type PIK3CA and KRAS alleles as NCl-H661 [24, 25]. More recently, studies have shown that inhibition of either AKT or mTOR signaling via the introduction of an endogenously mutated PIK3CA allele exacerbates invasiveness and EMT in the MCF10A breast cancer cell line [26].

However, in our experiments, the radiosensitizing effect of RAD001 was primarily observed in $\mathrm{NCl}-\mathrm{H} 661$ cells that possessed wild-type PIK3CA and KRAS genes, with only a marginal effect observed in $\mathrm{NCl}-\mathrm{H} 460$ cells. More recent work has also reported similar conflicting results. For example, Cai et al. found that mTORC1 inhibition suppresses EMT in colon and breast cancer cells via the specific inhibition of Snail (SNA/1) translation [27]. Although their overall conclusions are similar to ours, the study suggested that the effects of mTORC1 inhibition on EMT and cell motility were more pronounced in tumors with mutational activation of the AKT and ERK pathways. This study suggests that tumors with gene mutations in PI3K, PTEN, RAS, and RAF in the AKT and ERK pathways are highly dependent on mTORC1/4EBP1 signaling for the promotion of EMT, cell motility, and metastasis [27]. However, our results indicate that NSCLC cell lines with wild-type PIK3CA and KRAS alleles are more radiosensitive after inhibition of the MTORC1 pathway than cell lines with mutated genes. These slightly different conclusions are likely due to the different radiation doses and cell types used in the studies. For example, radiation can increase the metastatic potential of the lung cancer cell line A549 in vitro through EMTassociated events [28]. It has also been shown that tumor cells 

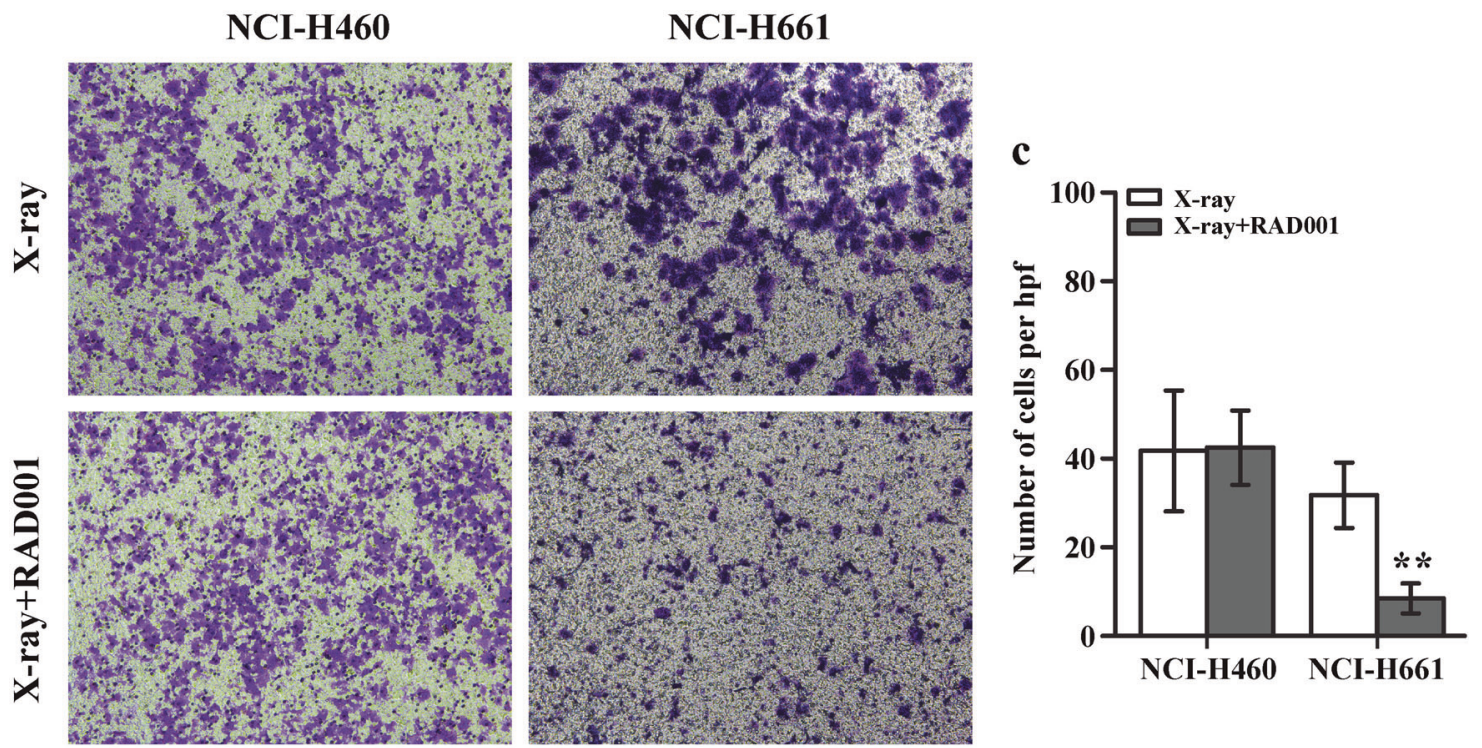

b

Invasion
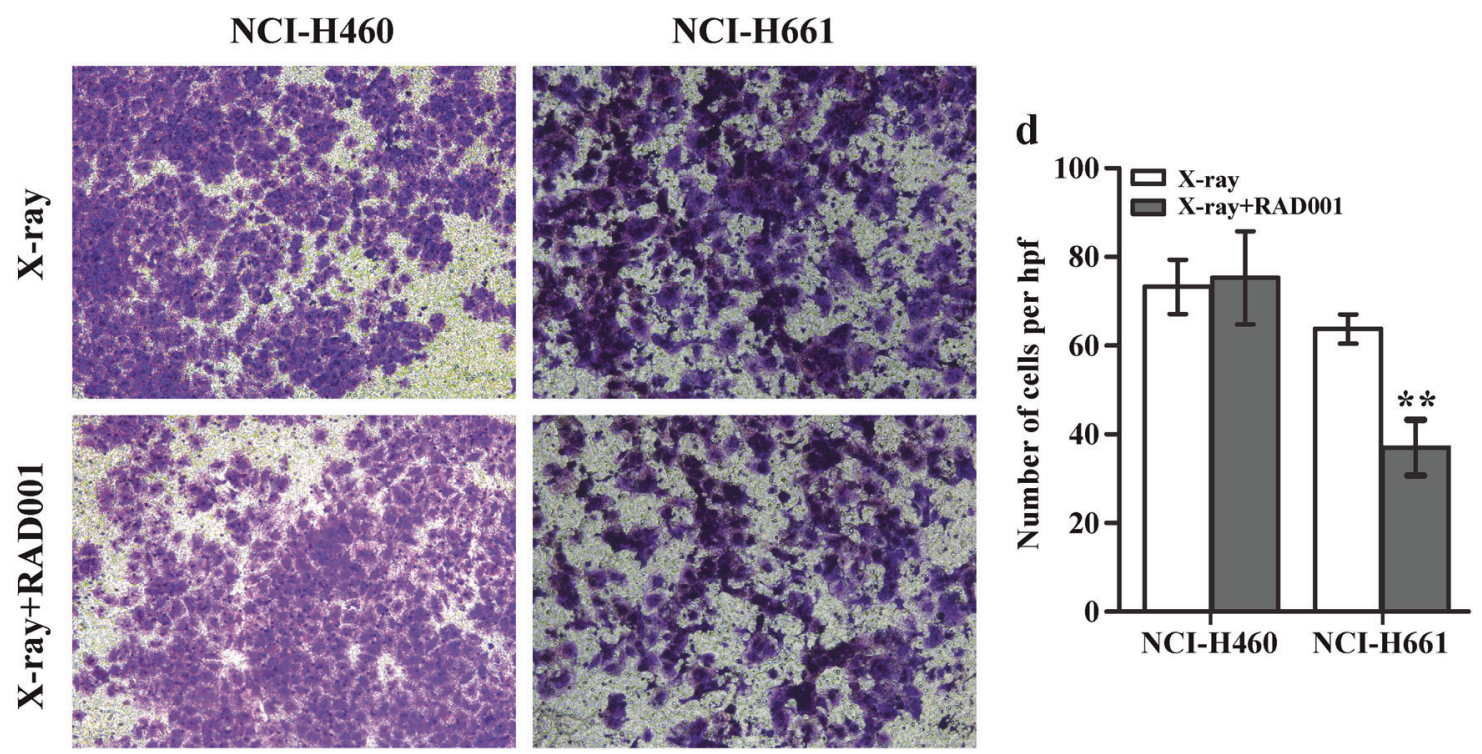

Fig. 5 Inhibition of mTORC1 decreases migration and invasion in $\mathrm{NCl}-\mathrm{H} 661$ cells after irradiation. $\mathbf{a}$, $\mathbf{b}$ The migration and invasion assays of the irradiated $\mathrm{NCl}-\mathrm{H} 460$ and $\mathrm{NCl}-\mathrm{H} 661$ cells with or without RAD001 pretreatment. c, d Summary graphs for migration and invasion, respectively. ${ }^{*} P<0.01$ vs. control. $n=4$

carrying oncogenic PIK3CA mutations are sensitive to RAD001, except when KRAS mutations are also present [20].

The $\mathrm{PI} 3 \mathrm{~K} / \mathrm{AKT} / \mathrm{mTOR}$ signaling pathway is related to the most frequently mutated genes in tumors [29]. However, there are many positive and negative feedback loops involved in the multiple signaling cascades that modulate mTOR activity, including the RAS/mitogen activated protein kinase (MAPK) pathway. The RAS/MAPK and PI3K/mTOR pathways are positively and negatively regulated by each other through extensive cross-talk [30]. Mutations in PI3K can act to continuously activate downstream pathways, promoting tumor cell proliferation and often leading to treatment resistance. PI3K is also a critical mediator of KRAS and is activated through multiple mechanisms in KRASmutant cells. KRAS itself can also bind directly to the p110a catalytic subunit of PI3K, thereby activating PI3K [31]. All of these interactions highlight the complexity involved in targeting the
$\mathrm{PI} 3 \mathrm{~K} / \mathrm{AKT} / \mathrm{mTOR}$ signaling pathway for the treatment of cancer. A previous phase I trial of RAD001 for NSCLC, in combination with thoracic radiotherapy, demonstrated a $41 \%$ partial response (PR), with $27 \%$ of patients developing progressive disease (PD) [32]. However, this clinical trial used an unselected population, and the genotypes of participants were unknown. Our results reveal that NSCLC cells with mutations in the PIK3CA and KRAS genes are insensitive to radiation with RAD001, suggesting that different approaches should be taken for patients with mutations in these genes. Approximately $25 \%$ of NSCLCs have a KRAS mutation, and $1 \%$ have a PIK3CA mutation [33]. This likely explains the moderate efficacy of RAD001 in the unselected population.

Our data also found that radiation can activate the mTOR pathway and increase the expression of p-p70S6K and EMTassociated proteins. Moreover, inhibition of $\mathrm{mTORC} 1$ can reduce radiation-induced $\mathrm{mTOR}$ pathway-associated protein 
a

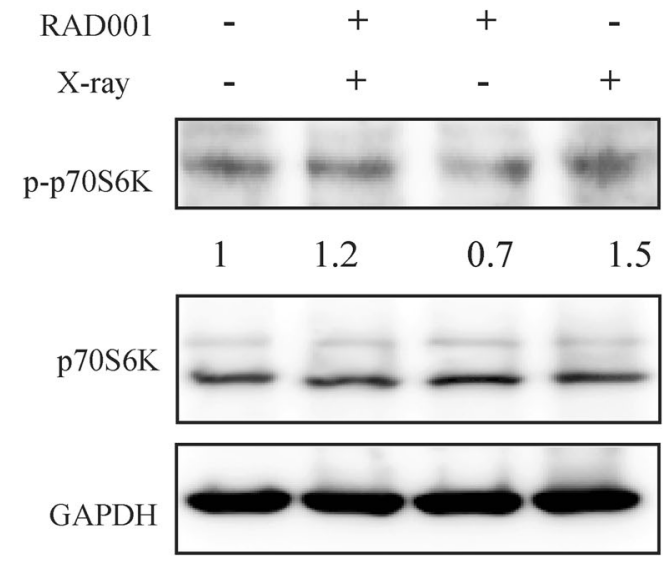

c

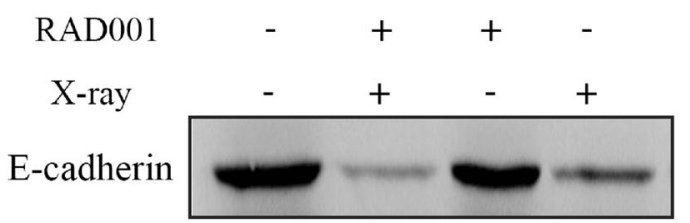

Vimentin

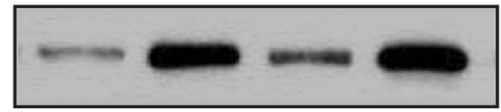

GAPDH

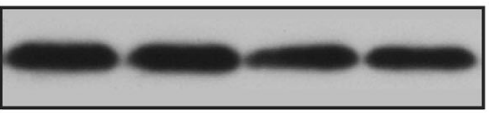

e

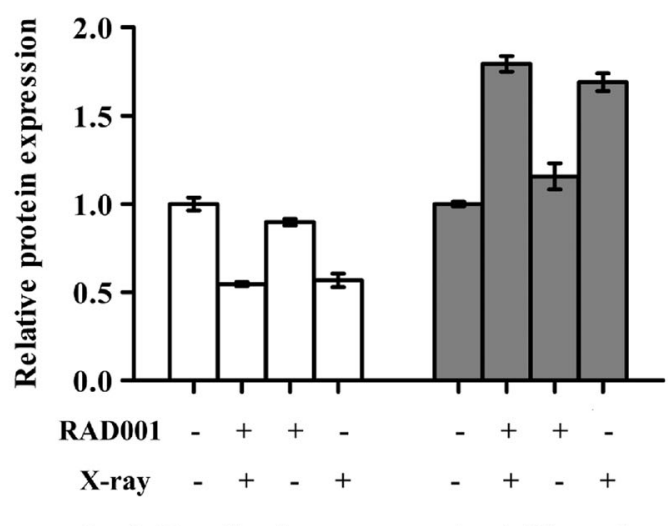

b NCI-H661

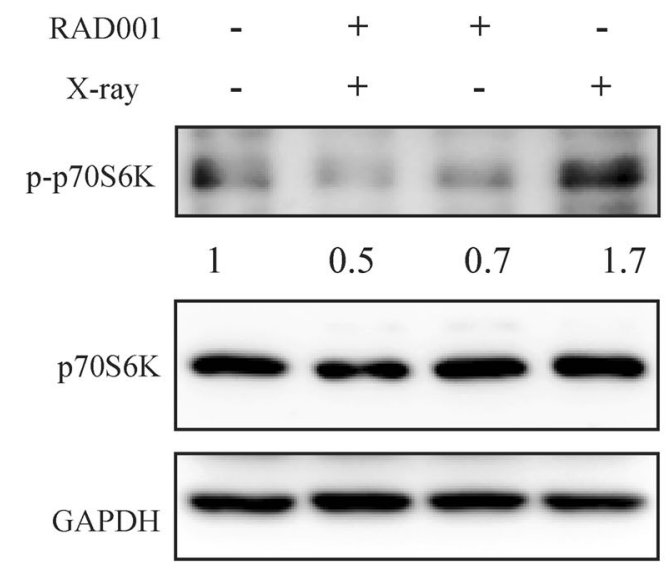

d

NCI-H661

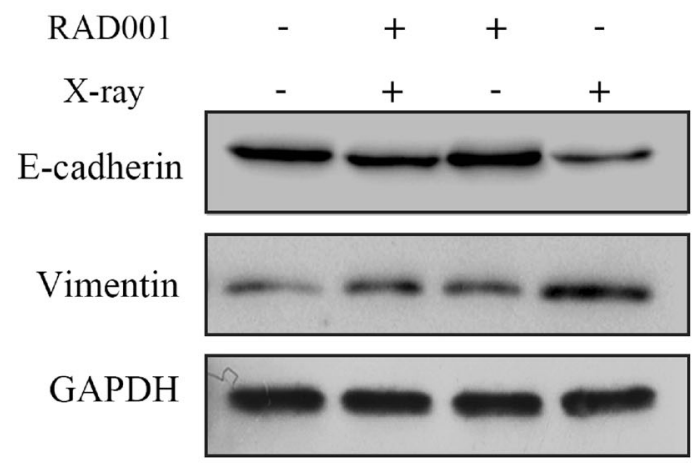

f

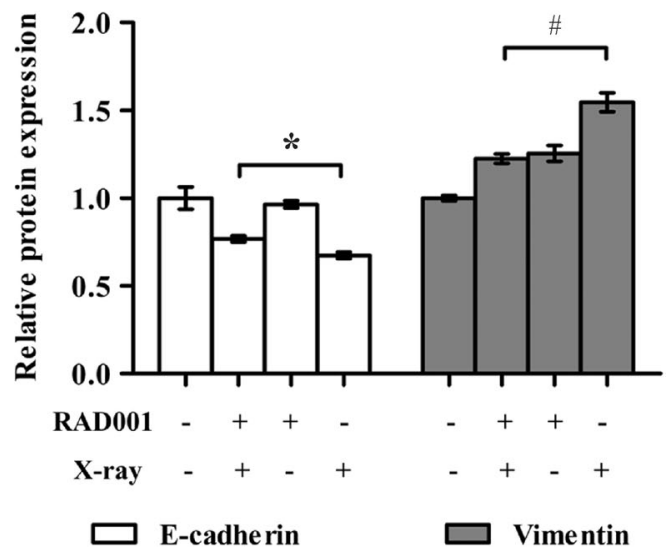

Fig. 6 Irradiation activates the mTORC1 pathway by altering EMT-associated genes and proteins in NSCLC cell lines. $\mathbf{a}$, $\mathbf{b}$ Effects of irradiation with or without a sensitization dose of RAD001 on the expression of p-p70S6K in NCl-H460 and NCl-H661 cells. c, d Immunoblot analysis of EMT markers in $\mathrm{NCl}-\mathrm{H} 460$ and $\mathrm{NCl}-\mathrm{H} 661$ cells incubated with or without $0.1 \mathrm{nM}$ RAD001 for $24 \mathrm{~h}$ before irradiation. e, f Analysis of relative protein expression in the two cell lines. ${ }^{*} P<0.05$ vs. the indicated groups. $n=3$

phosphorylation levels and radiotherapy resistance in some NSCLC cells, probably by modifying EMT. This process is often accompanied by E-cadherin loss, which was previously associated with cancer stem cells (CSCs). These sub-populations of cells are centrally involved in tumor relapse and radiation resistance [34, 35]. Additionally, it has been shown that mTORC1 signaling plays an essential role in supporting tumor cell growth and survival, as well as promoting genome instability at the onset of cancer [36]. Based on our experiments, we hypothesize that there is a relationship between mTORC1 signaling, EMT, and CSCs that is associated with tumorigenesis and radiation resistance. A novel therapeutic approach that uses EMT-signaling inhibitors would therefore be expected to alleviate radiotherapy resistance in NSCLC, although this requires further investigation in the future. Indeed, the precise mechanisms that underlie how mTORC1 inhibition regulates EMT and radioresistance are unclear. Further experiments are necessary to elucidate the downstream factors involved. In particular, determining how E-cadherin affects 


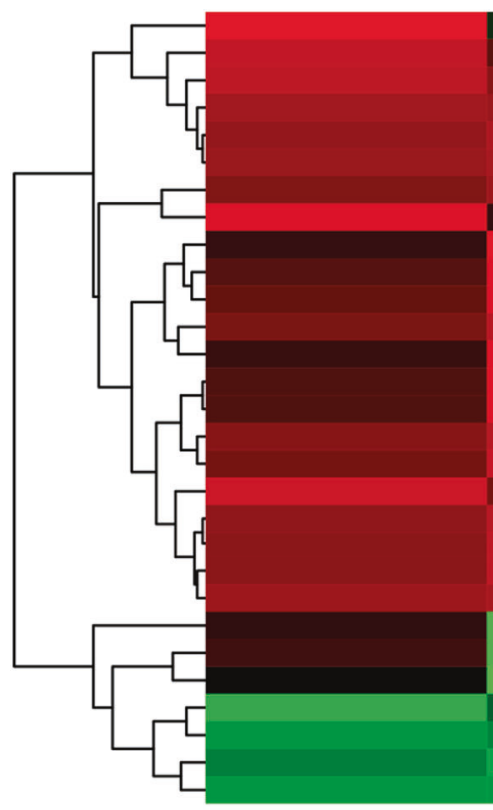

GSM266651

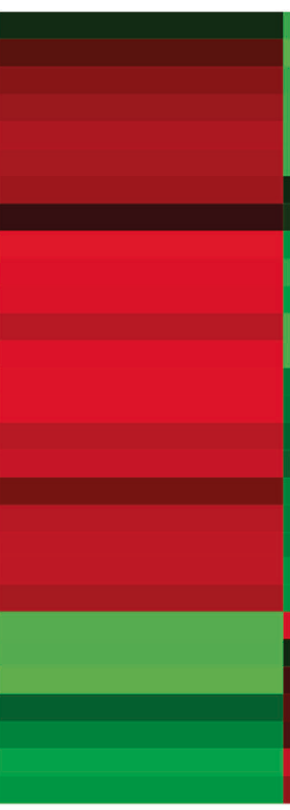

GSM266652

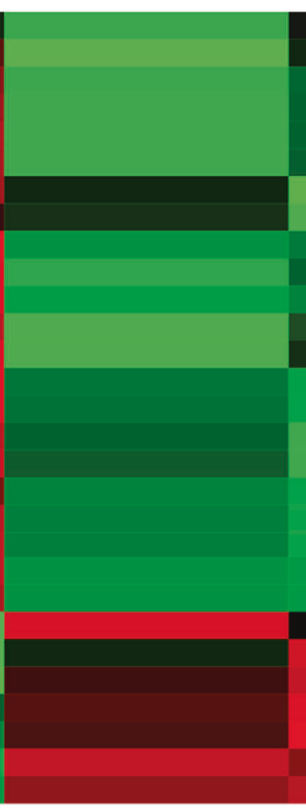

GSM266653

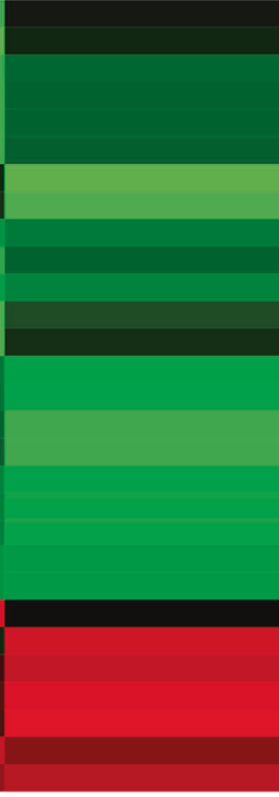

IKBKB SNAII TNFAIP1 PIK3CA RPS6KB1

SNAI2 LYK5 RHOA IGF1 FRAP1 PIK3R3 EIF4EBP1 MAPK3 CDH1 RHEB UBE2B
PIK3R4 PIK3R4 IFF TSC1 TWIST1 RPS6KB2 TSC2 RPS6KA1

Fig. 7 Heatmap analysis of mTOR and EMT signaling pathway transcripts after 2 Gy irradiation in HOP62 cells. GSM266651 and GSM266652: untreated Hop62; GSM266653 and GSM266654: Hop62 cells were treated with 2 Gy X-ray

radioresistance in NSCLC is of critical importance. A previous study reported that $\mathrm{PI} 3 \mathrm{~K} / \mathrm{mTOR}$ inhibition induced a positive feedback loop that dampened the efficacy of $\mathrm{PI} 3 \mathrm{~K} / \mathrm{mTOR}$ inhibition in metastatic breast cancer. PI3K/mTOR and JAK2 inhibition synergistically abrogated this feedback loop and reduced tumor growth [37]. Future work therefore needs to focus on understanding whether there are any feedback loops in NSCLC that are affected by PIK3CA and KRAS mutations and whether these feedback loops involve E-cadherin loss, CSC changes, or radioresistance. Our study was also limited by being performed in vitro, and further in vivo work is required to fully establish any links between mTOR, EMT, and radioresistance in NSCLC.

In conclusion, our experiments revealed that the mTORC1 signaling pathway is involved in regulating the radiosensitivity of some NSCLC cells. However, mTORC1 inhibition increased radiosensitivity and affected mTOR signaling downstream targets only in $\mathrm{NCl}-\mathrm{H} 661$ cells with wild-type PIK3CA and KRAS genes. mTORC1 inhibition could alleviate irradiation-specific EMT changes in NCl-H661 cells, suggesting that targeting mTORC1 may provide a potential new strategy for the treatment of NSCLC with wild-type PIK3CA and KRAS genes.

\section{ACKNOWLEDGEMENTS}

This study was supported by grants from the National Natural Science Foundation of China (no. 81772471) and the Qinghai Science \& Technology Department Funding (2017-ZJ-709).

\section{AUTHOR CONTRIBUTIONS}

YC, SX, and YC designed and performed the tissue and cellular experiments. YC, $\mathrm{W}$-WL, and PP performed the molecular experiments and gene expression analyses. YC and W-HZ performed the invasion and migration assays. YC and Y-JT contributed to writing the manuscript and the data analysis. YH provided important reagents. SX and YC designed the experiments, analyzed the data, wrote the manuscript, and provided the overall direction.

\section{ADDITIONAL INFORMATION}

Competing interests: The authors declare no competing interests.

\section{REFERENCES}

1. Vivanco I, Sawyers CL. The phosphatidylinositol 3-kinase AKT pathway in human cancer. Nat Rev Cancer. 2002;2:489-501.

2. Mckenna WG, Muschel RJ, Gupta AK, Hahn SM, Bernhard EJ. The RAS signal transduction pathway and its role in radiation sensitivity. Oncogene. 2003;22:5866-75.

3. Janku F, Yap TA, Meric-Bernstam F. Targeting the PI3K pathway in cancer: are we making headway? Nat Rev Clin Oncol. 2018;15:273-91.

4. Zoncu R, Efeyan A, Sabatini DM. mTOR: from growth signal integration to cancer, diabetes and ageing. Nat Rev Mol Cell Biol. 2011;12:21-35.

5. Guertin DA, Sabatini DM. Defining the role of mTOR in cancer. Cancer Cell. 2007;12:9-22.

6. Ma L, Chen Z, Erdjument-Bromage $H$, Tempst $\mathrm{P}$, Pandolfi PP. Phosphorylation and functional inactivation of TSC2 by Erk implications for tuberous sclerosis and cancer pathogenesis. Cell. 2005;121:179-93.

7. Thiery JP, Acloque H, Huang RY, Nieto MA. Epithelial-mesenchymal transitions in development and disease. Cell. 2009;139:871-90.

8. Shintani Y, Okimura A, Sato K, Nakagiri T, Kadota Y, Inoue M, et al. Epithelial to mesenchymal transition is a determinant of sensitivity to chemoradiotherapy in non-small cell lung cancer. Ann Thorac Surg. 2011;92:1794-804.

9. Kurrey NK, Jalgaonkar SP, Joglekar AV, Ghanate AD, Chaskar PD, Doiphode RY, et al. Snail and slug mediate radioresistance and chemoresistance by antagonizing p53-mediated apoptosis and acquiring a stem-like phenotype in ovarian cancer cells. Stem Cells. 2009;27:2059-68.

10. Gulhati P, Bowen KA, Liu J, Stevens PD, Rychahou PG, Chen M, et al. mTORC1 and mTORC2 regulate EMT, motility, and metastasis of colorectal cancer via RhoA and Rac1 signaling pathways. Cancer Res. 2011;71:3246-56.

11. Yamamoto $H$, Shigematsu $H$, Nomura $M$, Lockwood WW, Sato $M$, Okumura $N$, et al. PIK3CA mutations and copy number gains in human lung cancers. Cancer Res. 2008;68:6913-21.

12. Kharbanda A, Rajabi H, Jin C, Alam M, Wong KK, Kufe D. MUC1-C confers EMT and KRAS independence in mutant KRAS lung cancer cells. Oncotarget. 2014;5:8893-905.

13. Yonesaka K, Zejnullahu K, Lindeman N, Homes AJ, Jackman DM, Zhao F, et al. Autocrine production of amphiregulin predicts sensitivity to both gefitinib and cetuximab in EGFR wild-type cancers. Clin Cancer Res. 2008;14:6963-73.

14. Allred DC, Clark GM, Elledge R, Fuqua SA, Brown RW, Chamness GC, et al. Association of $\mathrm{p} 53$ protein expression with tumor cell proliferation rate and clinical outcome in node-negative breast cancer. J Natl Cancer Inst. 1993;85:200-6

15. Chu Q, Han N, Yuan X, Nie X, Wu H, Chen Y, et al. DACH1 inhibits cyclin D1 expression, cellular proliferation and tumor growth of renal cancer cells. J Hematol Oncol. 2014;7:73. 
16. Zhang L, Su B, Sun W, Li W, Luo M, Liu D, et al. Twist1 promotes radioresistance in nasopharyngeal carcinoma. Oncotarget. 2016;7:81332-40.

17. Liu Q, Li A, Yu S, Qin S, Han N, Pestell RG, et al. DACH1 antagonizes CXCL8 to repress tumorigenesis of lung adenocarcinoma and improve prognosis. J Hematol Oncol. 2018;11:53.

18. Kumaraswamy S, Chinnaiyan P, Shankavaram UT, Lü X, Camphausen K, Tofilon PJ. Radiation-induced gene translation profiles reveal tumor type and cancer-specific components. Cancer Res. 2008;68:3819-26.

19. Sos ML, Michel K, Zander T, Weiss J, Frommolt $\mathrm{P}$, Peifer $\mathrm{M}$, et al. Predicting drug susceptibility of non-small cell lung cancers based on genetic lesions. J Clin Invest. 2009;119:1727-40.

20. Di Nicolantonio F, Arena S, Tabernero J, Grosso S, Molinari F, Macarulla T, et al. Deregulation of the PI3K and KRAS signaling pathways in human cancer cells determines their response to everolimus. J Clin Invest. 2010;120:2858-66.

21. Theys J, Jutten B, Habets R, Paesmans K, Groot AJ, Lambin P, et al. E-Cadherin loss associated with EMT promotes radioresistance in human tumor cells. Radiother Oncol. 2011;99:392-7.

22. Zhang X, Li X, Zhang N, Yang Q, Moran MS. Low doses ionizing radiation enhances the invasiveness of breast cancer cells by inducing epithelial-mesenchymal transition. Biochem Biophys Res Commun. 2011;412:188-92.

23. Nam HY, Han MW, Chang HW, Lee YS, Lee M, Lee HJ, et al. Radioresistant cancer cells can be conditioned to enter senescence by mTOR inhibition. Cancer Res. 2013;73:4267-77.

24. Kim MR, Chang HW, Nam HY, Han MW, Moon SY, Kim HJ, et al. Activation of p53-p21 is closely associated with the acquisition of resistance to apoptosis caused by $\beta 1$-integrin silencing in head and neck cancer cells. Biochem Biophys Res Commun. 2012;418:260-6.

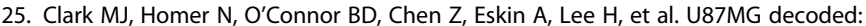
the genomic sequence of a cytogenetically aberrant human cancer cell line. PLoS Genet. 2010;6:e1000832.

26. Wallin JJ, Guan J, Edgar KA, Zhou W, Francis R, Torres AC, et al. Active PI3K pathway causes an invasive phenotype which can be reversed or promoted by blocking the pathway at divergent nodes. PLoS One. 2012;7:e36402.
27. Cai $W$, Ye $Q$, She $\mathrm{QB}$. Loss of $4 \mathrm{E}-\mathrm{BP} 1$ function induces $\mathrm{EMT}$ and promotes cancer cell migration and invasion via cap-dependent translational activation of snail. Oncotarget. 2014;5:6015-27.

28. Zhou YC, Liu JY, Li J, Zhang J, Xu YQ, Zhang HW, et al. lonizing radiation promotes migration and invasion of cancer cells through transforming growth factor-betamediated epithelial-mesenchymal transition. Int J Radiat Oncol Biol Phys. 2011;81:1530-7

29. Mayer IA, Arteaga CL. The PI3K/AKT pathway as a target for cancer treatment. Annu Rev Med. 2016;67:11-28.

30. Conciatori F, Ciuffreda L, Bazzichetto C, Falcone I, Pilotto S, Bria E, et al. mTOR cross-talk in cancer and potential for combination therapy. Cancers(Basel). 2018;10:E23

31. Yang Y, Ahn YH, Chen Y, Tan X, Guo L, Gibbons DL, et al. ZEB1 sensitizes lung adenocarcinoma to metastasis suppression by PI3K antagonism. J Clin Invest. 2014;124:2696-708.

32. Deutsch E, Le Pechoux C, Faivre L, Rivera S, Tao Y, Pignon JP, et al. Phase I trial of everolimus in combination with thoracic radiotherapy in non-small-cell lung cancer. Ann Oncol. 2015;26:1223-9.

33. Tsao AS, Scagliotti GV, Bunn PA Jr, Carbone DP, Warren GW, Bai C, et al. Scientific advances in lung cancer 2015. J Thorac Oncol. 2016;11:613-38.

34. Mani SA, Guo W, Liao MJ, Eaton EN, Ayyanan A, Zhou AY, et al. The epithelialmesenchymal transition generates cells with properties of stem cells. Cell. 2008;133:704-15.

35. Baumann M, Krause M, Hill R. Exploring the role of cancer stem cells in radioresistance. Nat Rev Cancer. 2008;8:545-54.

36. Xie $\mathrm{X}$, Hu $\mathrm{H}$, Tong $\mathrm{X}$, Li L, Liu X, Chen $\mathrm{M}$, et al. The mTOR-S6K pathway links growth signalling to DNA damage response by targeting RNF168. Nat Cell Biol. 2018;20:320-31.

37. Britschgi A, Andraos R, Brinkhaus H, Klebba I, Romanet V, Müller U, et al. JAK2/ STAT5 inhibition circumvents resistance to PI3K/mTOR blockade: a rationale for cotargeting these pathways in metastatic breast cancer. Cancer Cell. 2012;22:796-811. 